\title{
Seven years results in percutaneous closure of atrial septal defect and patent foramen ovale (single center experience)
}

\author{
Aleksandar Trbović*, Ksenija Kapov Sviličić, Robert Bernat \\ Clinic for Cardiovascular Diseases Magdalena, Krapinske Toplice, Croatia
}

Background: The aim of this report is to present 7 years results in percutaneous closure of atrial septal defect (ASD) and patent foramen ovale (PFO) in Magdalena hospital, and to assess the safety and efficacy of this procedure.

Methods: From April 2007 to March 2013, we performed transcatheter ASD and PFO closure in 58 consecutive symptomatic patients (pts). There were 34 percutaneous closures of ASDs and 24 percutaneous closure of PFOs.

Indication for ASD closure was significant left-to-right shunt associated with RV overload and mild to moderate pulmonary artery hypertension. Diameter of ASDs were in range from 12 to $28 \mathrm{~mm}$ (average diameter $17 \mathrm{~mm}$ ). For all pts. we used Occlutech Figulla ${ }^{\circledR}$ Flex ASD and PFO Closure Device (I and II generation) sized from 15 to $30 \mathrm{~mm}$. Closure of PFO was clinically indicated for secondary prevention in pts. with previous cryptogenic cerebrovascular events due to presumed paradoxical embolism.

Pre-procedurally thromboembolic events were: 19 ischemic strokes $(79 \%)$, and 5 transient ischemic attacks $(20.8 \%)$.

All procedures were performed with conscious sedation anesthesia under fluoroscopic and transesophageal echocardiography (TEE) guidance. Aspirin and clopidogrel were recommended at least for for 20 weeks after procedure for all patients.
Results: Primary success of percutaneous closure was achived in all patients.

The in-hospital complications were: self-limited supraventricular arrhythmia in 2 pts (3.4\%); paroxismal atrial fibrillation in 1 pts (1.7\%); minimal groin hematoma in 1 pts (1.7\%).

Control TEE pefomed after 20 weeks revealed mild residual shunt due to the lack of complite epitelisation of ocluder in 3 pts (5.1\%), and aspirin and clopidogrel were recommended for another 20 weeks. No device malfunction, erosion, valvular regurgitation or thrombus formation were occurred so far.

KEYWORDS: patent foramen ovale, atrial septal defect, transesophageal echocardiography, percutaneous closure device.

\section{Received: $20^{\text {th }}$ Mar 2013}

*Address for correspondence: Magdalena - klinika za kardiovaskularne bolesti, Ljudevita Gaja 2, HR-49217 Krapinske Toplice, Croatia.

Phone: +385-49-244-444

E-mail: trbovicsasa@gmail.com

\section{Literature}

1. Krizanic F, Sievert H, Pfeiffer D, Konorza T, Ferrari M, Hijazi Z, et al. The Occlutech Figulla PFO and ASD occluder: a new nitinol wire mesh device for closure of atrial septal defects. J Invasive Cardiol. 2010;22(4):182-7. 